\title{
Design of Low Voltage, Low Power (IF) Amplifier Based-On MOSFET Darlington Configuration
}

\author{
Hassan Jassim Motlak \\ Electrical Department, College of Engineering, Babylon University, Babylon, Iraq \\ Email: hssn_jasim@yahoo.com
}

Received April 20, 2013; revised May 21, 2013; accepted May 30, 2013

Copyright (C) 2013 Hassan Jassim Motlak. This is an open access article distributed under the Creative Commons Attribution License, which permits unrestricted use, distribution, and reproduction in any medium, provided the original work is properly cited.

\begin{abstract}
This paper presents a different approach of Intermediate Frequency (IF) amplifier using $0.18 \mu \mathrm{m}$ MIETEC technology channel length of MOSFET Darlington transistors. In contrast to Bipolar conventional Darlington pair, a MOSFET Darlington configuration is employed to reduce supply voltage $\left(\mathrm{V}_{\mathrm{DD}}\right)$ and $\mathrm{DC}$ consumption power $\left(\mathrm{P}_{\mathrm{c}}\right)$. The frequency response parameters of the proposed design such as bandwidth, gain bandwidth product, input/output noises and noise figure (NF) are improved in proposed (IF) amplifier. Moreover, a dual-input and dual-output (DIDO) IF amplifier constructed from two symmetrical single input and single output (SISO) (IF) amplifier is proposed too. The idea is to achieve improved bandwidth, and flat response, because these parameters are very important in high frequency applications. Simulation results that obtained by P-SPICE program are 1.2 GHz Bandwidth (BW), $3.4 \mathrm{GHz}$ (gain bandwidth product), $0.5 \mathrm{~mW}$ DC consumption power $\left(\mathrm{P}_{\mathrm{c}}\right)$ and the low total output noise is $12 \mathrm{nV} \sqrt{\mathrm{Hz}}$ with $1.2 \mathrm{~V}$ single supply voltage.
\end{abstract}

Keywords: N(IF) Amplifier; MOSFET Darlington Configuration; Dual-Input and Dual-Output (DIDO) IF Amplifier

\section{Introduction}

The communication market has been growing very fast during the last decade especially for mobile communication systems. The low power, low voltage and low noise (IF) amplifier is one of the most essential building blocks in the communication circuits. It can be found in the almost of the commercial and military receivers [1]. Several architectures of (IF) amplifier such as operational amplifier and Darlington pairs have been reported [2,3]. The most common used Darlington pair consists of an emitter-follower and a common-emitter bipolar transistors $[3,4]$. However, a major drawback is encountered with its performance. At higher frequencies its response becomes poorer than that of a single transistor amplifier [5]. To overcome this problem, a number of modifications are attempted in Darlington pair amplifiers either by adding some extra biasing resistances in the circuit or by using Triple Darlington topology the earlier published Darlington amplifiers [5-8]. All previous work still suffers from high DC consumption power due to high value of collector current, high noise and limitation in bandwidth. In this paper, a simple circuitry high performance single input and single output (SISO) (IF) amplifier based on $(0.18 \mathrm{um})$ channel length MOSFETs Darlington configuration is proposed. The proposed amplifier used small channel-length $(0.18 \mu \mathrm{m})$ to overcome the problems in consumption power, limitation in bandwidth, and inter-electrode capacitances. Because the small channel length of MOSFETs reduced the effect of inter-electrode capacitances at high frequency operation of MOSFETs. Besides that the reducing channel length will reduce the value of threshold voltage of MOSFETs and capable the designer to use small value of supply voltage and supply current. A dual-input and dual-output (DIDO) (IF) amplifier constructed from two symmetrical (SISO) (IF) amplifiers is proposed in this approach. The proposed dual-input and dual output (DIDO) (IF) amplifier is important in vast area of mobile applications such as multiband, wideband, and high-isolation multiple-input multiple-output techniques.

\section{Design of Single Input and Single Output (SISO) IF Amplifier}

Figure 1 shows the schematic circuit diagram of the proposed (IF) amplifier based on MOSFET Darlington configuration. The proposed amplifier constructed from two stages using NMOS transistors, biasing voltage and biasing resistors. The values of biasing resistors includ- 


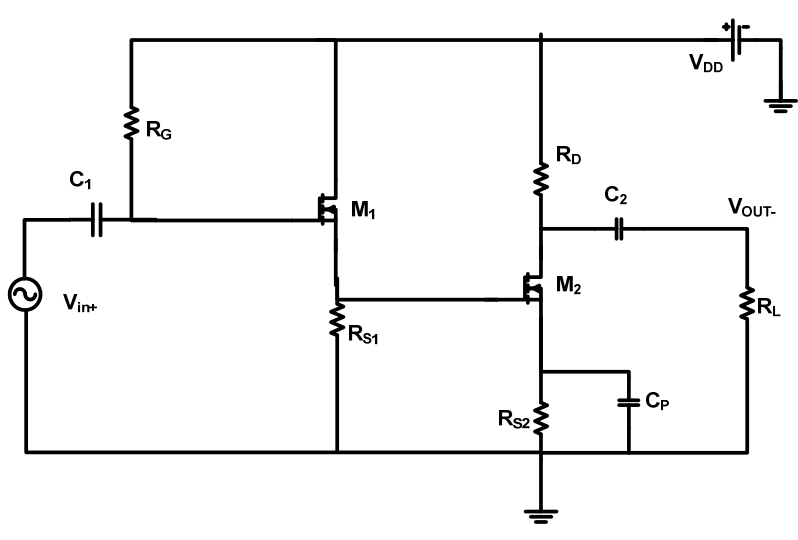

Figure 1. Schematic diagram of single-stage (IF) amplifier.

ing $R_{G 1}, R_{S 1}, R_{D 2}$, and $R_{S 2}$ can be calculated using dc analysis of two stages separately. In this design, the value of dc consumption power is very important for low power consideration, so that we have to choose suitable values of supply voltage $V_{D D}$ and biasing current $I_{D}$. We can find the value of aspect ratios $\left(\frac{W}{L}\right)$ of two NMOS transistors using drain current equation for MOSFET as follows [9]:

$$
I_{D}=K_{n} \frac{W}{L}\left(V_{G S}-V_{T}\right)^{2}
$$

where, $K_{n}$ is a channel length modulation parameter, $V_{G S}$ is the gate to source voltage and $V_{T}$ is the threshold voltage of MOSFET transistors.

The change in drain current that will results from a change in gate-to source voltage can be determined using the transconductance factor $\left(g_{m}\right)$ in the following expression:

$$
g_{m}=\frac{\partial I_{D}}{\partial V_{G S}}=2 K_{n} \frac{W}{L}\left(V_{G S}-V_{T}\right)
$$

The transconductance factor is important in calculating the value of voltage gain, current gain and gain-bandwidth product (GBP) of the (IF) amplifier.

The ac small-signal equivalent circuit of the design configuration is shown in Figure 2. The overall voltage $A_{V}$ of the small signal equivalent circuit is given by:

$$
A_{V}=\frac{V_{\text {out }}}{V_{\text {in }}}=\left(\frac{g_{m 1} R_{S 1}}{1+g_{m 1} R_{S 1}}\right) \times\left(-g_{m 2} \times\left(r_{d 2} / / R_{D 2}\right)\right)
$$

We note that the value of $A_{V}$ depend on the value of second term of Equation (3), if the value of factor $g_{m 1} R_{S 1} \gg 1$, the value of overall voltage gain is given by:

$$
A_{V}=-g_{m 2} \times R_{D 2}
$$

To investigate the effect of the external capacitors (blocking capacitors $\left(C_{1}, C_{2}\right)$ and by pass capacitor $\left(C_{P}\right)$ ) and internal capacitors $C_{G S}, C_{G D}$, and $C_{D S}$ on frequency response of the (IF) amplifier in low and high frequencies following expressions of cut off frequencies is used:

$$
f_{L}=\frac{1}{2 \pi R_{e q} C_{P}}
$$

In low frequencies the largest cut-off frequency of the amplifier is determined by bypass capacitor $\left(C_{P}\right)$ and equivalent resistor as illustrated in Equation (5). The value of equivalent resistor is given by:

$$
R_{e q}=\frac{1}{g_{m}} / / R_{S}
$$

where, $R_{e q}$ is the equivalent resistance looking by source terminal of MOSFET in (IF) amplifier .

The analysis of the high-frequency response of the proposed (IF) amplifier using high frequency equivalent circuit is shown in Figure 3.

1) The cut-off frequency of the overall voltage gain for the input circuit is defined by following expression:

$$
f_{H i}=\frac{1}{2 \pi R_{T h i} C_{i n 1}}
$$

where $R_{T h i}$ is the Thevenins resistance of input circuit and $C_{i n 1}$ is the total input capacitance included inter electrode $\left(C_{G S}\right)$ and wiring capacitance $\left(C_{w i}\right)$.

2) The cut-off frequency of the overall voltage gain for the output circuit is defined by following expression:

$$
f_{\text {Ho }}=\frac{1}{2 \pi R_{\text {Tho }} C_{\text {ou } 1}}
$$

where $R_{\text {Tho }}$ is the Thevenins resistance of output circuit and $C_{o}$ is the total output capacitance included inter electrode capacitance $\left(C_{G D}\right)$ and wiring capacitance $\left(C_{w o}\right)$.

From Equations (7) and (8), we note that the interelectrode capacitances of MOSFET transistors are play important role in determining the frequency response of (IF) amplifier in high frequencies. These capacitances defined by gate dimensions of MOSFET, so that we can extend the value of upper-cut-off frequency by suitable choose of technology $0.18 \mu \mathrm{m}$ channel-length of MOSFET. Our design confirms this concept as we see in simulation results. The gate dimensions of NMOS transistors and biasing currents of the proposed (IF) amplifier are given Table 1.

\section{Design of Dual-Input, Dual-Output (DIDO) (IF) Amplifier}

The dual-input, dual-output (DIDO) (IF) amplifier plays important role in several mobile applications such as multiband, wideband, and high-isolation multiple-input multiple-output techniques [10]. The proposed (DIDO) (IF) amplifier is based on simple circuitry approach with high performance parameters compared with conventional amplifiers. The design idea of proposed dual-input 


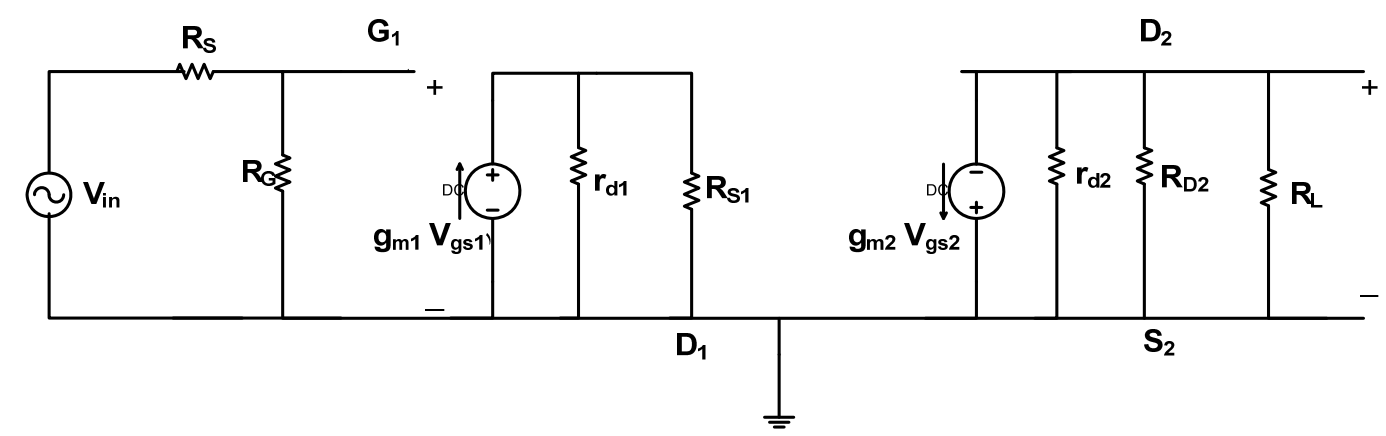

Figure 2. Small-signal equivalent circuit of MOSFET Darlington configuration.

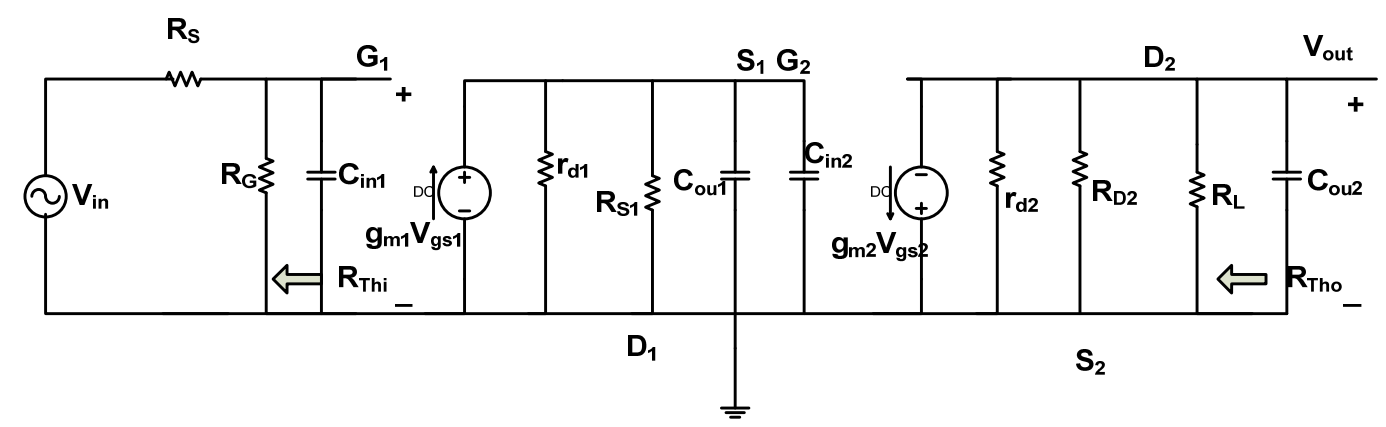

Figure 3. High frequency ac equivalent circuit for proposed (IF) amplifier.

Table 1. Gate dimensions and biasing currents of MOSFETs for proposed (SISO) (IF) amplifier in Figure 1.

\begin{tabular}{cccc}
\hline \multirow{2}{*}{ Transistor's number } & \multicolumn{3}{c}{ Gate dimensions and basing currents } \\
\cline { 2 - 4 } & $\begin{array}{c}\text { Gate width } \\
\mathrm{W}(\mu \mathrm{m})\end{array}$ & $\begin{array}{c}\text { Channel length } \\
\mathrm{L}(\mu \mathrm{m})\end{array}$ & $\begin{array}{c}\text { Biasing current } \\
(\mu \mathrm{A})\end{array}$ \\
\hline $\mathrm{M}_{1}$ & 1.75 & 0.18 & 17.6 \\
$\mathrm{M}_{2}$ & 1.75 & 0.18 & 396.3 \\
\hline
\end{tabular}

(DIDO) (IF) amplifier based on constructed two symmetrical single (IF) amplifier using face-to-face connection as shown in Figure 4.

\section{Simulation Results}

The frequency response of the proposed amplifier that characterized by flat voltage gain and wide bandwidth is shown in Figure 5, where the maximum value of the voltage gain is $7.6 \mathrm{~dB}$. Figure 6 shows the phase response of the voltage gain. The input and output noises of the proposed (IF) amplifier is shown in Figure 7. As can be seen in measurement, values of input/output noises are increased with increasing the frequency of output voltage and current but still in acceptable range due to high noise immunity of MOSFET technology that used in proposed (IF) amplifier. The value of output current delivered to the resistive load used in proposed (IF) amplifier is decreased as $\mathrm{R}_{\mathrm{L}}$ varied from $10 \mathrm{k} \Omega$ to 100 $\mathrm{k} \Omega$. The value of output current is varied from $560 \mu \mathrm{A}$ to $10 \mu \mathrm{A}$ as load resistor is varied from $10 \mathrm{k} \Omega$ to $100 \mathrm{k} \Omega$ as can be seen in Figure 8.

Figures 9 and 10 show the frequency response (phases) and (magnitudes) of the dual-input and dual-output (DIDO) (IF) amplifier. We note that the frequency response in same values for both outputs (positive and negative) with phase difference is $180^{\circ}$. Moreover, the transient time response shown in Figure 11 of DIDO (IF) amplifier for both outputs (positive and negative) are in same value with phase difference is $180^{\circ}$ too. Figures 9-11 prove that the DIDO (IF) amplifier operates as we expected in theoretical background.

Figure 12 shows the harmonic measurements of DIDO (IF) amplifier. In this figure, the value of harmonic distortion is increased due to increasing in frequency. To decrease the effect of harmonic distortion source degeneration technique can be used.

Table 2 shows the performance parameters of the proposed (IF) amplifier compared with other designs in previous works. The simulation results of the proposed amplifier verify the excellent improvement in dc consumption power, and low supply voltage. 


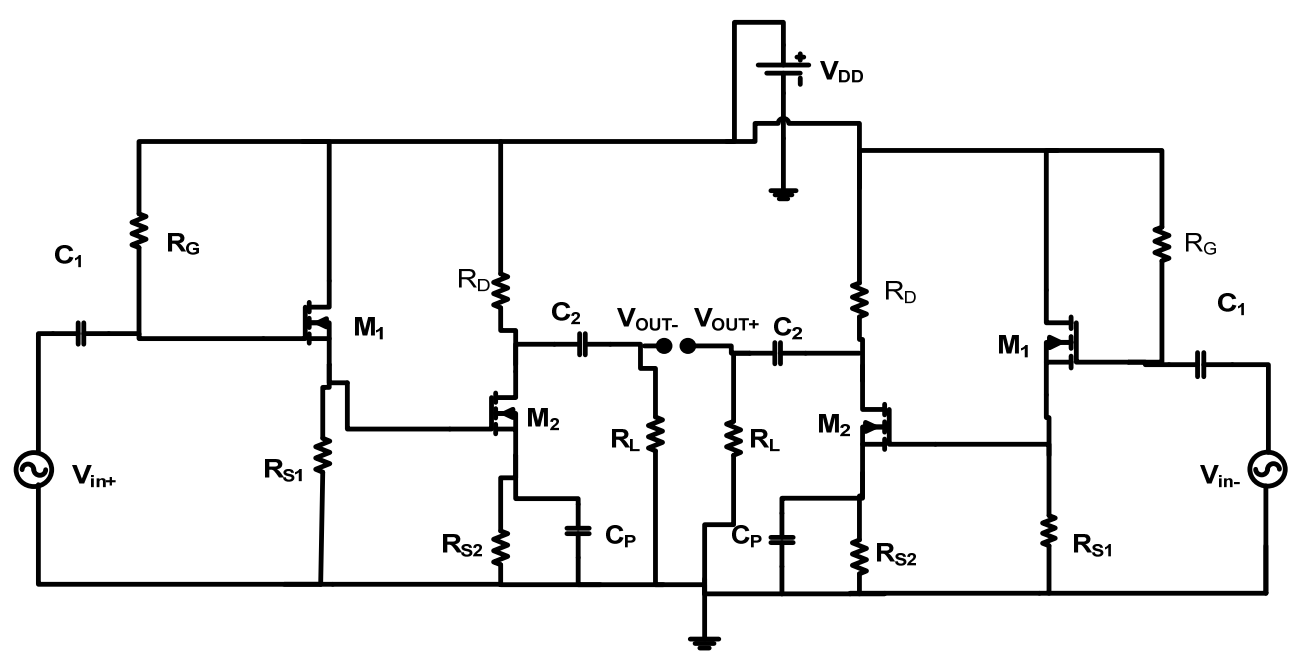

Figure 4. Schematic diagram of DIDO (IF) amplifier.

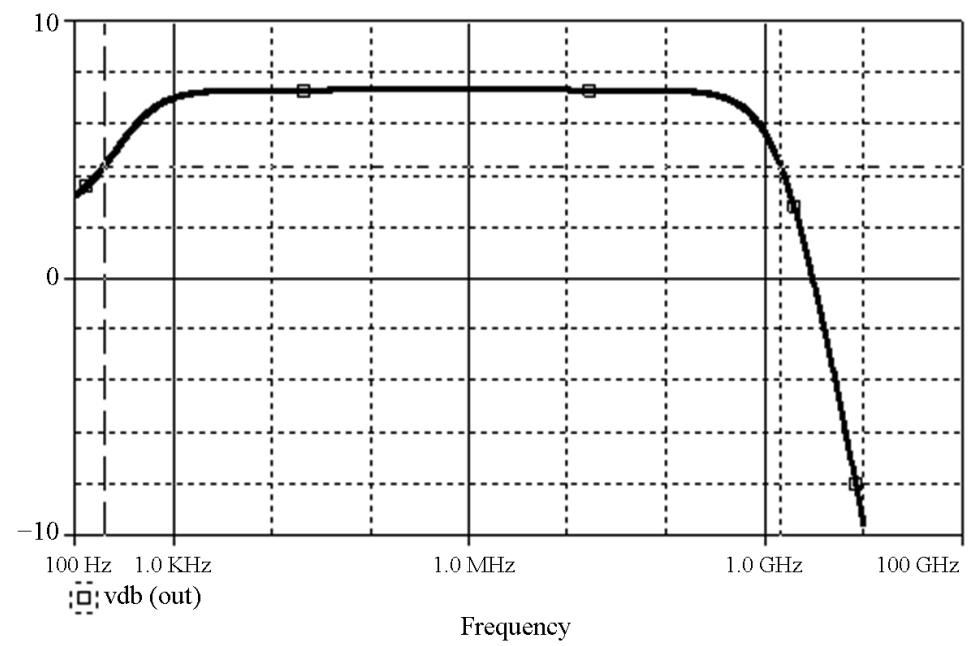

Figure 5. Frequency response (magnitude of voltage gain) of single (IF) amplifier.

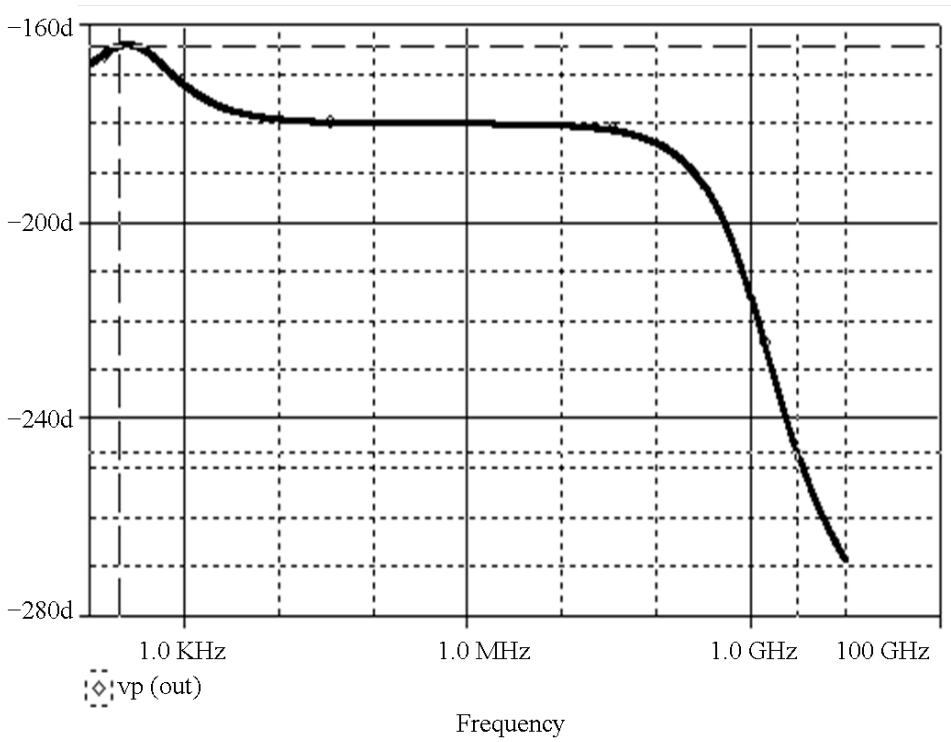

Figure 6. Frequency response (phase of voltage gain) of single (IF) amplifier. 


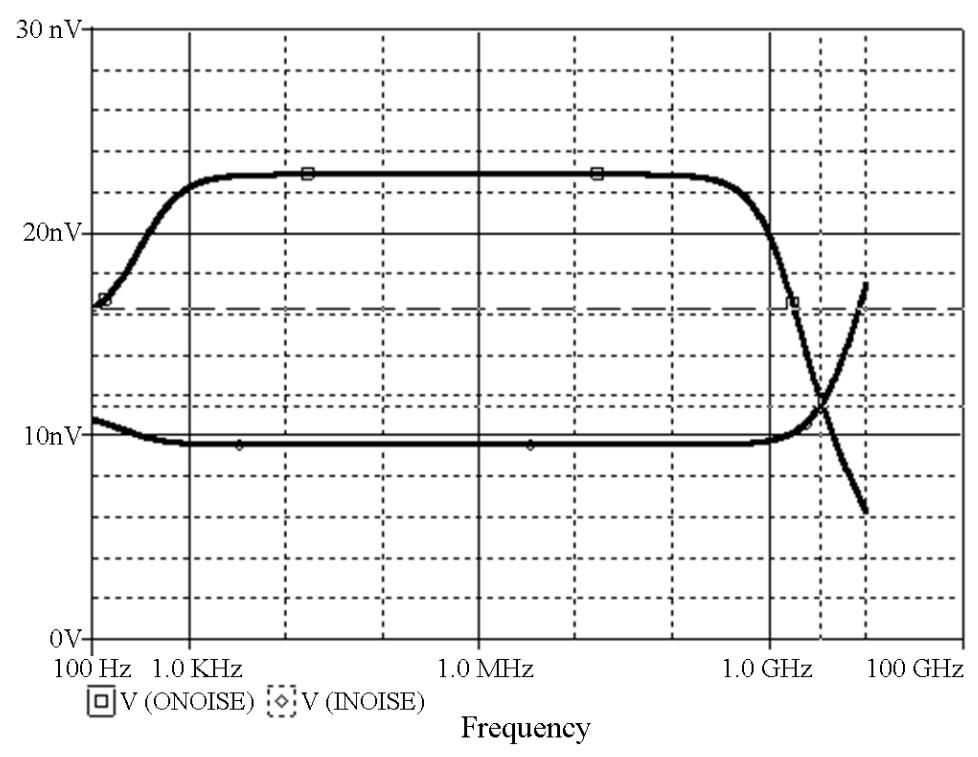

Figure 7. Input and output noises of proposed (IF) amplifier.

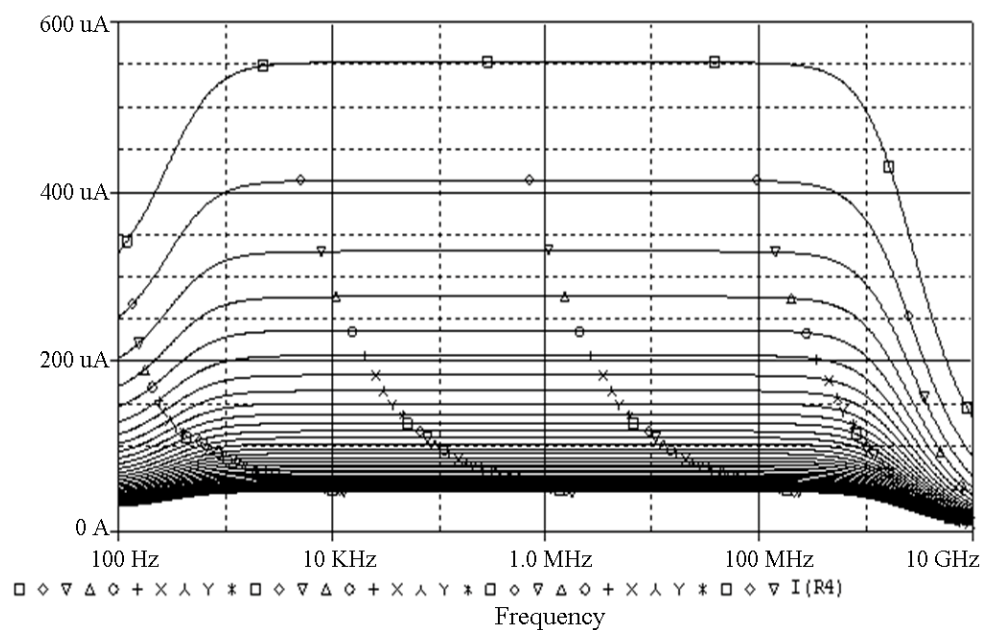

Figure 8. Frequency response of output current as $R_{L}$ is varied from $10 \mathrm{k} \Omega$ to $100 \mathrm{k} \Omega$ of the proposed (IF) amplifier.

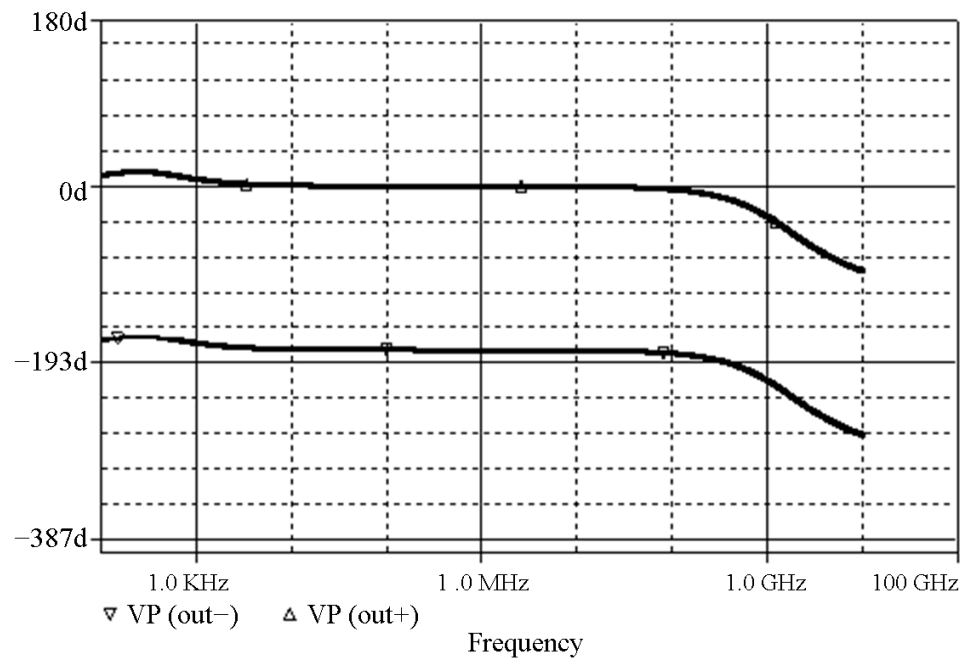

Figure 9. Frequency responses (phases) of positive and negative outputs of the proposed DIDO (IF) amplifier. 


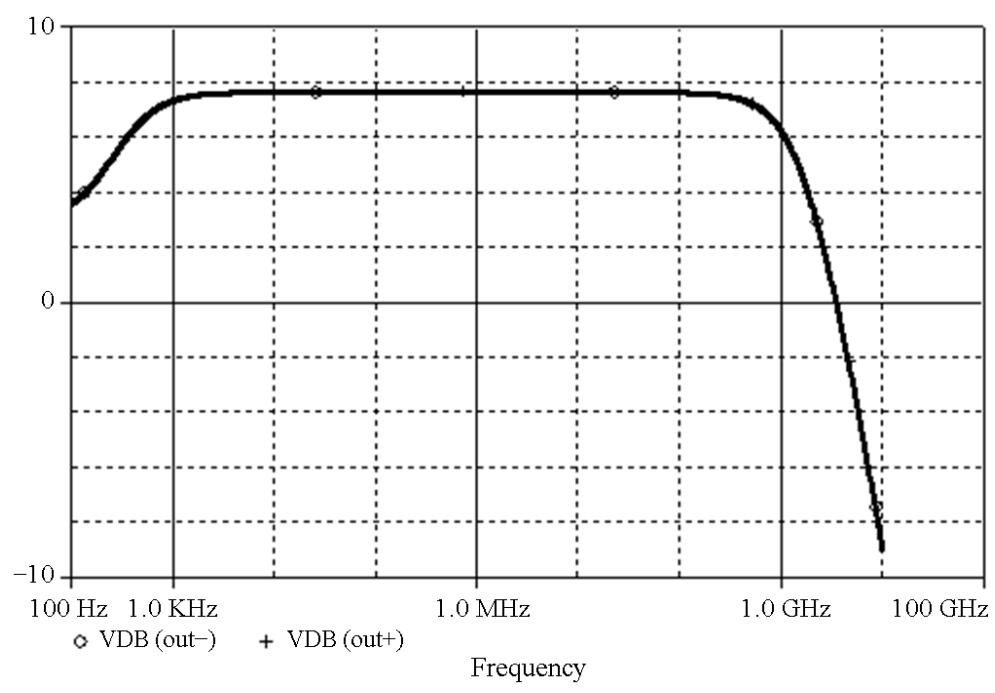

Figure 10. Frequency responses (magnitude) of positive and negative outputs of the proposed DIDO (IF) amplifier.

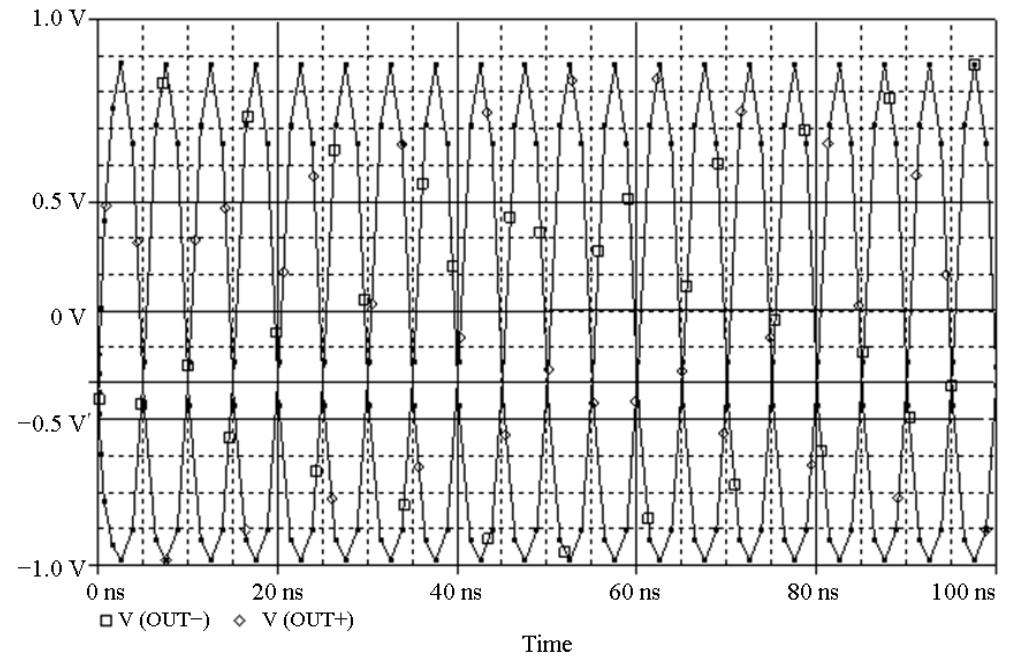

Figure 11. Transient response of positive and negative outputs of the proposed DIDO (IF) amplifier.

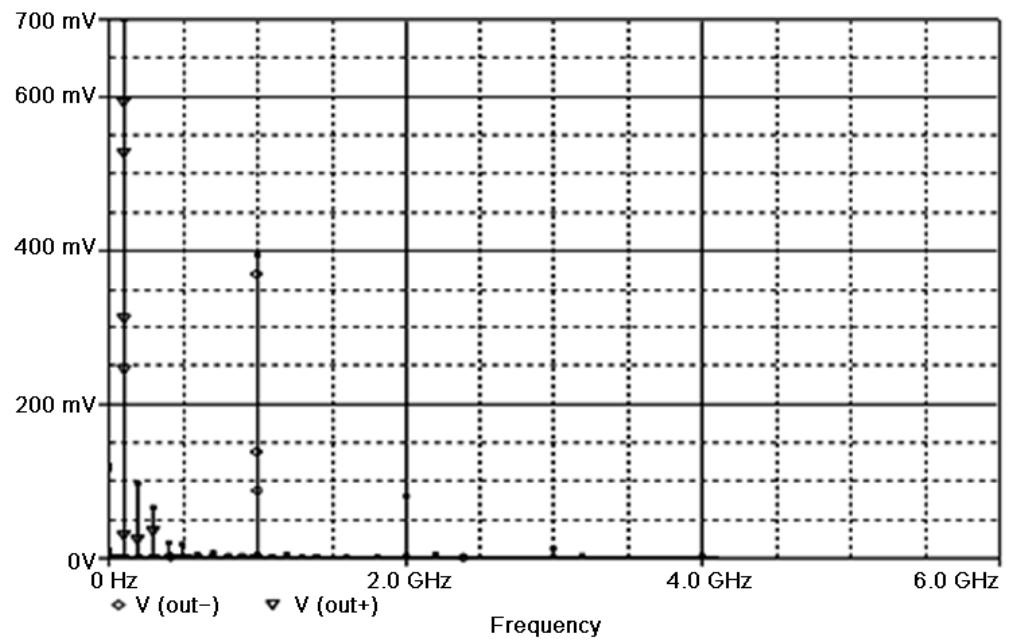

Figure 12. 3HD measurement of positive and negatives outputs of the proposed DIDO (IF) amplifier with different frequencies of input voltages. 
Table 2. Summarized the performance parameters of the proposed (IF) amplifier compared with previous designs.

\begin{tabular}{cccc}
\hline \multirow{2}{*}{ Performance parameters } & \multicolumn{3}{c}{ Previous work compared with proposed (IF) amplifier } \\
\cline { 2 - 4 } & (IF) amplifier proposed by [7] & (IF) amplifier proposed by [6] & (IF) amplifier of Figure 1 \\
\hline Technology & PHEMT FETs & 2- $\mu$ m GaAsHBT BJTs & $(0.18 \mu \mathrm{m})$ MOSFET \\
\hline GBP $(\mathrm{GHz})$ & 1.0 & 19.0 & 3.0 \\
Voltage Gain $\left(A_{v}\right)(\mathrm{dB})$ & 15.5 & 12.8 & 7.6 \\
Supply voltage $\mathrm{V}_{\mathrm{DD}}(\mathrm{V})$ & 5.0 & 10.0 & 1.2 \\
Consumption power $(\mathrm{mW})$ & 500 & 150 & 0.5 \\
Noise Figure $(\mathrm{NF})(\mathrm{dB})$ & 2.0 & - & 5.6 \\
\hline
\end{tabular}

\section{Conclusion}

Single input and single output low voltage and low power (IF) amplifier based on Darlington configuration is designed in this work. Minimum channel length (0.18 $\mu \mathrm{m})$ of MOSFET Darlington transistors is used to improve the performance of MODFETs in high frequency operation, and to reduce the effects of parasitic capacitance of MOSFETs in high frequency operation. Moreover, the decreasing of channel length of MOSFETs reduces the value of power supply of the circuit and the consumption power because the threshold voltage of MOSFETs has become smaller. A dual-input and dual output (DIDO) (IF) amplifier constructed from two symmetrical single input single output (IF) amplifier is also proposed in this paper. A wide bandwidth around $(1.2 \mathrm{GHz})$, wide gain bandwidth product around (3.0 $\mathrm{GHz})$, low supply voltage $(1.2 \mathrm{~V})$, and low consumption power around $(0.5 \mathrm{~mW})$ are achieved in this proposed design. The drawback of this design is low voltage gain around $(7.6 \mathrm{~dB})$, but it can be increased using feedback technique or using triple stage Darlington configuration.

\section{REFERENCES}

[1] El-S. A. M. Hasaneen and N. Okely, "On-Chip Inductor Technique for Improving LNA Performance Operating at 15 GHz," Circuits and Systems, Vol. 3, No. 4, 2012, pp. 334-341. doi:10.4236/cs.2012.34047

[2] P. Kakoty, "Design of a High Frequency Low Voltage CMOS Operational Amplifier," International Journal of VLSI Design \& Communication Systems (VLSICS), Vol. 2, No. 1, 2011, pp. 73-85. doi:10.5121/vlsic.2011.2107
[3] A. Motayed and S. N. Mohammad, "Tuned Performance of Small-Signal BJT Darlington Pair," Solid-State Electronics, Vol. 45, 2001, pp. 369-371. doi:10.1016/S0038-1101(00)00247-1

[4] C. Arnott, "Wideband Gain Block Amplifier Design Techniques," Applied Microwave \& Wireless, 2001, pp. 98109.

http://data.eefocus.com/myspace/0/2029/bbs/1192675584 /23b66dea.pdf

[5] S. N. Shukla and S. Srivastava, "Small-Signal Amplifier with Three Dissimilar Active Devices in Triple Darlington Topology," International Journal of Advanced Research in Electrical, Electronics and Instrumentation Engineering, Vol. 1, No. 6, 2012, pp. 502-508.

[6] C.-S. Lin, M.-D. Tsai, H. Wang, Y.-C. Wang and C.-H. Chen, "A Monolithic HBT Broadband Amplifier Using Modified Triple Darlington Configuration," $12^{\text {th }}$ GAAS Symposium, Amsterdam, 2004, pp.331-334.

[7] H. Cebi, "A High Linearity Darlington Intermediate Frequency (IF) Amplifier for Wide Bandwidth Applications," Microwave Journal, Vol. 53, No. 11, 2011, pp. 18-24.

[8] A. M. H. Sayed ElAhl, M. M. E. Fahmi and S. N. Mohammad, "Quantitative Analysis of High Frequency Performance of Modified Darlington Pair," Solid-State Electronics, Vol. 46, No. 4, 2002, pp. 593-595. doi:10.1016/S0038-1101(01)00308-2

[9] R. L. Boylestad, L. Nashelsky and F. J. Monssen, "Electronic Devices and Circuit Theory," 8th Edition, Prentice Hall, Upper Saddle River, 2002.

[10] S.-H. Kim, Z.-J. Jin, Y.-B. Chae and T.-Y. Yun, "Small Internal Antenna Using Multiband, Wideband, and HighIsolation MIMO Techniques," ETRI Journal, Vol. 35, No. 1, 2013, pp. 51-57. doi:10.4218/etrij.13.0112.0183 